\title{
Editorial
}

\section{ENERGY, A MAJOR OVERSIGHT IN THE CIRCULAR ECONOMY AND RESOURCE MANAGEMENT?}

With the threat of resource depletion, the idea of "Circular Economy" has virally spread in recent years as a "buzzword" with a positive symbolic charge. It has become essential in order to define modern waste management, not only in Europe but also abroad, such as in China. However, there is no single and commonly accepted definition of this concept. This one always seems simple and attractive with the image of an eternal cycle or a closed loop of our resources in a perfect circle.

Many questions then arise around this almost miraculous idea: "Is it really a closed circle?", "How large is the circle of the circular economy?", "How to transform this concept into a concrete, scientific and measurable project?", "What are the essential raw materials on which we depend?", "How can we keep the circular economy clean?", and finally, "Where is the energy to make this "wheel" turn smoothly and is this energy circular? ». Energy is the fundamental "detail" not to be forgotten, because there are no resources, no economy, not even life without energy! Perpetual motion does not exist, just like infinite recycling or zero waste. Leonardo da Vinci's beautiful inventions such as the helicopter remained motionless for more than 4 centuries in the absence of the energy source able to animate them.

Before sketching out some answers to these questions, let's start with the origins of the concept of circular economy. It surprisingly is a Chinese invention from the early 2000s. First identified in the Chinese scientific literature in 2003 (Bartl, 2019), the principle of circular economy was firstly adopted at the regulatory and legislative level by China. Its national strategy for the management of its resources and waste is based on this notion. It first appeared in its 11th five-year plan in 2006, then in its "Law for the Promotion of the Circular Economy" in 2008. Articles 2 and 15 of this law give a definition of the "generic term of circular economy describing the activities of reducing, recycling and resource recovery in production, circulation and consumption" and above all ask to "recycle those wastes articles if possible, or otherwise make harmless treatment if they cannot be reused due to economic or technical restrictions". The result of this policy has been the rapid and significant development of non-recyclable Waste-to-Energy (WtE) plants in this country as a fundamental pillar of China's Circular Economy law. The installed capacity in China in just over a decade has now exceeded that of Europe built in more than a century (Hanwei-Zhang, 2019).

In the same state of mind, due to the lack of some nat- ural resources, Japan has also adopted similar legislation called "3R (Reduce, Reuse, Recycle) for a sound material cycle society in Japan". The separate collection of large number of material streams for recycling is taken there to the extreme. Nevertheless, as in China, the final outlet for the treatment of residual and non-recyclable waste is based on energy recovery with a thousand $\mathrm{WtE}$ facilities. Ten years after China, the concept of circular economy was introduced in Europe in the 2018 European directive on waste (EUR-Lex, 2018) which defines it as: "Improving the efficiency of resource use and ensuring that waste is valued as a resource can contribute to reducing the Union's dependence on the import of raw materials and facilitate the transition to more sustainable material management and to a circular economy model". After these definitions, let's come back to our questions.

\section{"Is this a perfect closed circle?"}

The ideal of a cyclic system, while desirable, is unrealistic for many reasons. The different materials are intentionally mixed in the production phase of the products or unintentionally mixed as waste. This leads to an inevitable decline in their quality for each additional use. There is no such thing as infinite recycling. Moreover, every step involves leakage and therefore residues to be treated. Anthropogenic stocks are also an important underestimated topic in circular economy discussions. Approximately $50 \%$ of all extracted resources are used to build up new anthropogenic stocks. (Mavropoulos, 2020). Finally, the circular economy narrative focuses explicitly on raw materials and ignores the growing energy demands for the development of closed loops. Yet $15-20 \%$ of the extracted resources are energy carrier resources which cannot be replaced by secondary materials. This is why the more precise concept of use cascades was introduced (ISWA, 2015). But it has not been as attractive as that of the circular economy.

\section{"How large is the circle of circular economy?"}

A major ambiguity is hidden here. The territorial dimension of the circular economy is indeed one of the crucial issues to be considered. On the one hand, we hear about a very micro and local vision, of circular cities or dwellings. Some are dreaming of autonomous cities able to feed their inhabitants with the promotion of urban gardening supported by domestic compost of our kitchen waste in front of each building. The principle of proximity is indeed a good tool for obtaining solutions adapted to the metabolism of 
cities, especially regarding waste management. On the other hand, the macro and worldwide vision corresponds more to the reality of our globalised economy. The value chains of most consumer products have long since been globalised with resources and industries relocated beyond our national or European borders. Europe is now the continent with the fewest sovereign resources, especially for non-renewable ones. For resources, materials, energy carriers or raw secondary materials, the circular economy cannot therefore be well designed either locally or globally. With 2018's "China ban", Europe and USA have experienced the rejection of materials that are recyclable according to us but considered of poor quality by Asian countries. It has also shown that these recycled materials must find an outlet within the continent which produced them. The European directive's objective of reducing the Union's dependence on the import of raw materials shows us that the sovereignty of a country or continent like Europe is the right dimension of the "circle" of the circular economy. This 'national' approach is very much in line with the vision of the circular economy of countries such as China.

"How to transform this concept into a concrete, scientific and measurable project?"

Measurement and progress indicators are essential and the recycling rate, which is the focus of attention in Europe, is not sufficient on its own. In addition to this one, some others have been implemented in China and Japan, such as resource productivity (GDP/natural resource input) and the amount of waste in final disposal in landfills. Socalled Sankei diagrams provide a vision of the different involved flows and the circularity of the economy of each country or of the European Union. It shows for example for metals the EU's net important dependence on imports of metals ores, but also its mitigation through a high recycling rate (Mayer, 2019). One should not forget that one of the main drivers of circular economy should be economy! This should be also an efficient tool to measure progress.

\section{"What are the essential raw materials on which we depend most?"}

While the EU's economy is almost self-sufficient in the supply of non-metallic minerals (construction materials) and biomass, an examination of EU's trade reveals a clear asymmetry between physical imports and exports for the
2 other main categories of materials (see Figure 1 - EUROSTAT, 2019). We have seen above that imports assigned to the category of metal ores amount to around 0.5 tonnes per capita and are almost twice as large as their exports. But this is nothing compared to European extreme dependence on fossil primary energy sources. Imports of fossil energy materials are both the most important (with more than 2 tonnes per capita) and the most unbalanced (as physical imports are about four times larger than exports). Therefore, it doesn't make sense, for the EU to import its fossil fuels and then export oil in the form of recycled plastic when it could be used for productive purposes. It makes even less sense to landfill plastics or metals when they could at least be respectively converted into energy or recovered after the Waste-to-Energy process. This WtE treatment method relieves this deficit balance with local, mostly renewable and non-intermittent energy.

\section{"How to keep the circular economy clean?"}

Quality recycling means protecting the circular economy from hazardous substances and keeping it clean. Non-recyclable waste contains contaminated materials and substances that are health and safety hazards. They must be safely removed from circulation. These materials can be safely destroyed by combustion while recovering energy. WtE has a crucial and unique role in the complete destruction of organic hazardous materials, in the reduction of risks due to pathogenic microorganisms and viruses and in the concentration of valuable metals as well as toxic metals in certain fractions. This is its role as a safe and final sink for pollution mitigation (Brunner, 2015). Combustion of contaminated streams in large (hazardous or clinical waste) or more diffuse (municipal waste) quantities in well-equipped facilities is the best available solution thanks to the advanced pollution control technologies of state-of-the-art flue gas cleaning systems. This avoids the contamination of the circular economy by avoiding the recycling of pollution that could have an impact on both the environment and the human health. Indeed, this issue has motivated the moratorium of Asian countries on our so-called recyclable materials exported to Asia. Their mediocre quality in relation to their standards could not allow their insertion in their circular economy, therefore leading them to requalify them as waste.

\section{Physical imports and exports by main material category, EU-27, 2019 (tonnes per capita)}

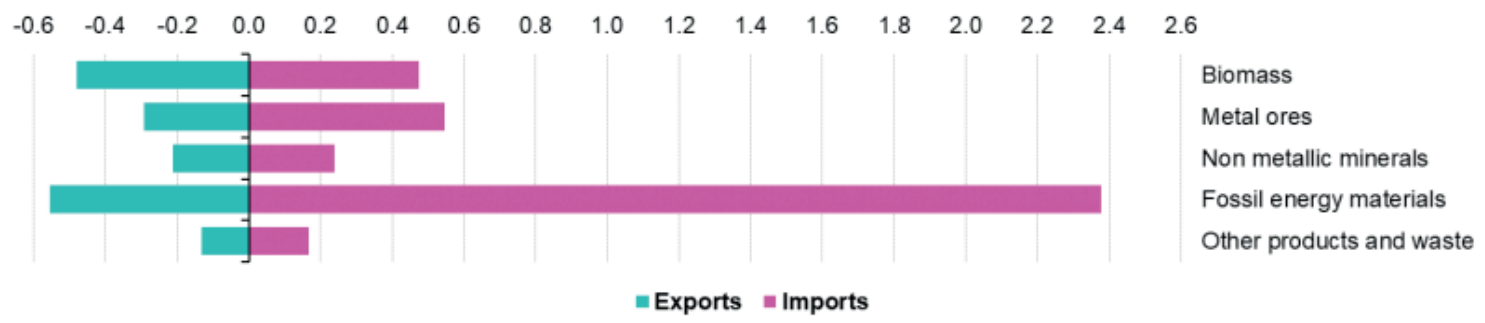

Source: Eurostat (online data code: env_ac_mfa; demo_gind)

eurostat?

FIGURE 1: Physical imports and exports by main material category in EU 27, 2019 (tonnes per capita). 
"Where is the energy to make this "wheel" turn smoothly and is it circular?"

Due to the current abundance of chemical and thermal energy sources represented by fossil fuels, we are no longer aware of our dependence and the super-powers that this concentrated and cheap energy affords us. The mechanical energy that a man can develop with his muscles alone is very limited and very expensive (Jancovici, 2020) Indeed, the average daily muscular work capacity of a man is limited to about $0.25 \mathrm{kWh} /$ day (FAO, 2021), i.e. about $100 \mathrm{kWh} /$ year with an estimated marginal cost in Europe of around 200EUR/kWh. 1 litre of fuel oil contains $10 \mathrm{kWh}$ of thermal energy, i.e. the equivalent in mechanical energy of the daily work of about ten men. However, each European consumes an average of 10 litres per day (average primary energy consumption per European people $100 \mathrm{kWh} /$ day - 3toe/capita/year). (Eurostat, 2020). Thanks to this cheap energy, all the machines often used unconsciously by everyone every day thus provide us with the equivalent of the muscular work of a hundred men at the service of each European inhabitant with a marginal cost per mechanical $\mathrm{kWh}$ of around 500 times cheaper with these machines. This energy has given us "inexpensive" super-powers that are obviously ephemeral!

We are not aware of all this energy involved in the creation and distribution of products as well as in the treatment of our waste, which will always hinder the achievement of total Circular Economy. Most of this energy is doomed to be linear as shown in the attached diagram (see Figure 2). The idea of transforming all waste into materials comes back, so to speak, to the alchemy of transmuting lead into gold, which is impossible just as perpetual motion without energy. We could face a bottleneck on production even with plenty of capital or work if we have a bottleneck on

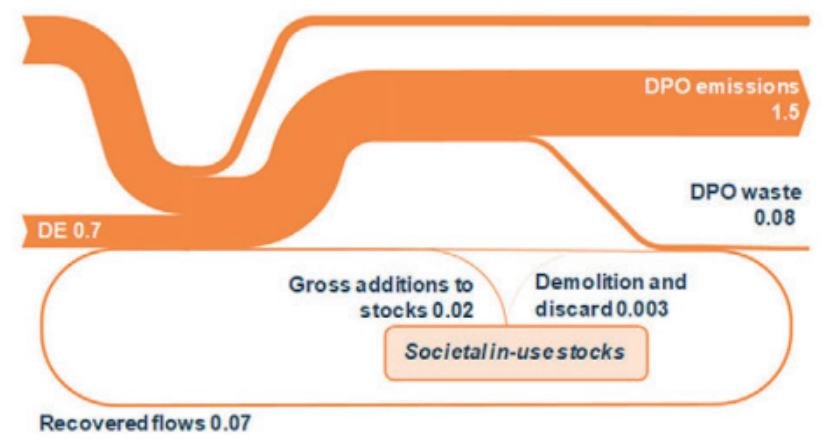

FIGURE 2: Fossil energy materials flows through the EU28 economy. In this Sankey diagram, the width of the arrows is proportional to the size of material flows; the numbers show the size of the material flows in Gt/yr. (DE = domestic extraction, $\mathrm{DPO}=$ domestic processed output) - Source: (Mayer, 2019). energy. Same for biodiversity. Nothing will be fished even with plenty of boats and fishermen if no gasoline (energy) or no fish (biodiversity). No production without energy and biodiversity. Bottlenecks are where we don't look at.

The pandemic and situations of lockdown and scarcity have recently and cruelly reminded us of the importance of these principles of sovereignty over our resources and of proximity of tools to meet our vital needs. This crisis has shown how essential the continuity of public waste management services is, as a basic human need, part of the "metabolism" of cities. Waste contains resources rich in materials and energy. In each $\mathrm{kg}$ of residual waste that each European produces every day, there is about $2.5 \mathrm{kWh}$ of thermal energy available that WtE facilities recover safely while eliminating the pollution resulting from the mixture of materials we consume. Here is found circular energy which keeps circular economy clean!

\section{Christophe Cord'Homme \\ CNIM Environment \& Energy, France \\ ccordhomme@cnim.com}

\section{REFERENCES}

Bartl. (2019). The eu circular economy package: Are new paths being taken or is it an old story? Sardinia 2019.

Brunner. (2014). Waste to energy, key element for sustainable waste management. Waste management.

European Parliament. (2018). Directive (EU) 2018/851 of the European Parliament on waste. Retrieved from https://eur-lex.europa.eu/ legal-content/EN/TXT/?uri=uriserv:OJ.L_.2018.150.01.0109.01. ENG

EUROSTAT. (2019). Physical_imports_and_exports. Retrieved from https://ec.europa.eu/eurostat/statistics-explained/index.php/ Physical_imports_and_exports\#Import_dependency

Eurostat. (2020). Energie primaire . Retrieved from https://ec.europa. eu/eurostat/databrowser/view/t2020_33/default/table?lang=fr

FAO. (2021). Force motrice humaine. Retrieved from http://www. fao.org/3/ah810f/AH810F08.htm\#: :text=Les\%20besoins $\% 20$ \%C3\%A9nerg\%C3\%A9tiques\%20alimentaires\%20s,200\%20 \%C3\%A0\%20300\%20Wh\%2Fjour

Hanwei-Zhang. (2019). World Waste to Energy and Resources London. World Waste to Energy and Resources London. London.

ISWA Task force. (2015). Report 5: CIRCULAR ECONOMY : Energy and fuels. ISWA

Jancovici. (2012). How to Improve Energy Efficiency with Circular Economy. Retrieved from University of Bradford: https://www.youtube. com/watch?v=IRAMA4mT0z0

Mavropoulos, A. (2020). Industry 4.0 and circular economy. ISWA

Mayer. (2019). Measuring Progress towards a Circular Economy (jiec.12809)

Ministry of the Environment of Japan. (2006). Japan's experience in promotion of the 3R's .

Republic of China. (2008). Circular Economy Promotion Law of the People's Republic of China. Retrieved from http://english.mep.gov.cn/ Resources/laws/envir_elatedlaws/201712/t20171212_427823. shtml 